\title{
Grenzen der Menschheit
}

\author{
En tekst fra Grundtvig-arkivet
}

udgivet af William Michelsen

Da en udgivelse af Grundtvigs efterladte papirer lader vente på sig, kan det være på sin plads at udgive enkelte tekster fra Grundtvig-arkivet i Grundtvig-Studier. Årsagen til valget af den efterfølgende tekst er, at den dokumenterer Grundtvigs forhold til den samtidige idealistiske filosofi, set i relation til kristendommen. Den eneste samtidige filosof, der nævnes, er Schelling, men det drejer sig ikke blot om ham, men om en tendens $i$ filosofien, som Grundtvig fører tilbage til oldtidens gnostikere. Det drejer sig om forholdet mellem filosofi og religion, og udgangspunktet for Grundtvigs holdning er Goethes digt Grenzen der Menschheit, som han har afskrevet med tydeligt prentede bogstaver i sin dagbog, og som ikke handler om menneskehedens udstrækning, men om menneskets grænser. Holdepunktet for Grundtvigs tanker er Johannesevangeliet, hvis græske tekst han ønskede skulle være udgangspunkt for læsningen af Det nye Testamente på originalsproget.

Manuskriptet adskiller sig fra de fleste af teksterne i Grundtvig-arkivet ved sine mange overstregninger og rettelser, mest af sproglig art, som her er udeladt. At det er skrevet på tysk, må skyldes at det er den tyske filosofi, Grundtvig først og fremmest forholder sig til. Det er en "Auseinandersetzung ", en enetale som svar på Schellings enetale, et indlæg i samtidens debat om religionen, i særdeleshed kristendommen og dens forhold til filosofien. Da denne debat mest førtes - og stadig føres - på tysk, er det naturligt nok, at Grundtvig her skriver på tysk, hvad han jo ikke er vant til. Deraf de mange rettelser. - Man kan beklage, at Grundtvig ikke offentligt benyttede sig af samtidens og eftertidens filosofiske sprog. Det var et principielt standpunkt, der afholdt ham derfra, som det ses af tidsskriftet Danne-Virke. For at lette oversigten og forståelsen er der tilføjet en dansk oversættelse. - Datering 1816-18. 


\title{
Grenzen der Menschheit
}

\author{
Ein bisher ungedrucktes Manuskript von \\ N.F.S. Grundtvig
}

Nicht das Goethische Gedicht, das unter dieser Ueberschrift so berühmt geworden, sondern das Räthsel selbst, das der Dichter, nicht nur Goethe, sondern der Dichter überhaupt lebendig darstellt, diess wunderbare Räthsel, wodurch der Mensch sich selbst ein Wunder ist, wollen wir betrachten, um zu sehen, ob es sich selbst löset, oder ob die Erwartung davon unter den eiteln Hoffnungen, die nimmer erfüllt werden können, zu zählen und zu verweisen ist. Es scheint ja wohl thöricht im Ernst zu fragen, ob ein wunderbares Räthsel sich selbst löset, aber wenn doch der Mensch sich nach Jahrtausenden noch mit der Hoffnung schmeichelt sein Daseyn zu ergründen, das heisst, sich in sich selbst zu fassen und zu begreifen, dann thut es ja Noth, die helle Wahrheit, wo möglich, noch heller, oder doch einleuchtender darzustellen, und wenn es auch nicht zu erwarten steht, Blindgeborne durch das Licht zu heilen, möchten doch wohl einige, die sich selbst im Lichte stünden, wenn es ihnen einleuchtet, sich umkehren und es klüger finden ihre eigne Thorheit jetzt zu belachen, als einst zu beweinen.

Der Mensch nun, der wenn er anfängt über sich selbst zu denken, dünkt sich Wunder was er alles ist, was ist er wohl, recht beym Lichte besehen an und für sich selbst? Staub und Asche, sagt Abraham, Thon in der Hand des Töpfers, spricht Esaias, wiederholt Paulus, und haben wohl die Philosophen aller Jahrhunderte etwas, auch nur das Geringste mehr aus ihrem Bewusstseyn heraus, an das Licht hervor gebracht? Ich denke mit nichten, denn es frägt sich hier nicht, was sie träumten oder wähnten, nicht was sie inner oder ausserhalb des Bewusstseyns, als etwas Fremdes, Hinein geschobenes gefunden oder gemuthmasst haben, sondern nur was mehr ans Licht gefördert, sichtbar geworden ist, denn nur das, wenn irgend etwas, darf der Mensch sein Eignes nennen, als in seinem Selbst-Bewusstseyn 
vorhanden annehmen, und sagen: das hab ich nicht nur, sondern das bin ich, das ist mein Ich, und kann sich selbst als solches betrachten und darstellen.

Dasz der Mensch in sich selbst nur ein Körper sey, das nennen ja wohl die meysten heutigen Philosophen eine Unwahrheit, die man nicht wiederholen kann, ohne der Wahrheit eben so wohl als dem Menschen Hohn zu sprechen, aber manche von den scharfsinnigsten Köpfen haben es doch eingestanden, und ihre Widersacher vergeblich aufgefordert, ihnen etwas Anderes als den Menschen selbst vor Augen zu stellen, oder unläugbar zu beurkunden. Die Idealisten behaupten freilich, dasz es nur deshalb unmöglich ist weil es den Realisten oder Materialisten an dem Auge gebricht, womit man den innern, geistigen Menschen, als den einzig wahren erblickt, aber dieses eingestanden, müsste sichs ergeben, dass, wenn auch einzelne Menschen, doch nicht der Mensch überhaupt, nicht das Geschlecht in sich selbst mehr als ein Körper sey, und dass also der Mensch in sich selbst theilweise mehr sey als im Ganzen, welches in dem menschlichen Selbst-Bewusstsein einen wahren Widerspruch, das heisst: eine wahre Unmöglichkeit voraussetzte. Wollen also die Idealisten die Ehre des selbstsüchtigen Menschen ohne Widerspruch behaupten, müssen sie alle, die in sich selbst nur einen Körper erblicken, für Unmenschen erklären, für eine Spiel-Art des Affen-Geschlechtes, die den Menschen zwar ganz natürlich nachäfft, $j a$ in Gedanken nachbildet und diese Gedanken menschenähnlich in Wörtern einkleidet, die aber doch gar nicht zum Menschen-Geschlechte gehört, weil sie in dem denkenden, redenden Menschen nicht sich selbst, sondern nur einen gedankenfähigen wortführenden Körper schauen, weil sie den unkörperlichen Gedanken-Schmied und Wort-Bildner in sich selbst nicht erblicken. Auch so verwickeln sie sich aber in unverantwortliche Widersprüche, und besonders ist es klar, das sobald unsrer einer sagt, ich erblicke in mir selbst zwar mehr als einen Körper aber nur weil ich in dem Körper mehr erblicke als er an und für sich selbst ist, weil ich ihn als das Gegenbild einer höheren Gestalt betrachte, dann können die Idealisten dem Sprecher den Menschen-Namen nicht verweigern, weil das einzige Merkmal des wahren Menschen, laut ihren eignen Worten, das Geständnis war, mehr als einen Körper in dem Menschen zu sehen, und hier 
haben sie da wieder einen Menschen, der ihren Satz, dass der Mensch mehr als ein Körper ist, völlig umstosst. Darum schlug sich die kritische Philosophie ins Mittel, und behauptete, dass der Mensch mehr als ein Körper seyn müsste, weil der KörperBegriff ihn gar nicht erschöpfe, auch nicht, wenn er ihm genügte, und daher müsse er ihm auch nicht genügen; was er in sich selbst nicht erblickte, obgleich es sich in ihm unläugbar kund thut, das müsse er voraussetzen: postuliren. Das ist nun unläugbar, man kann sich aber nicht genug über die Eitelkeit des Menschen verwundern oder betrüben, wenn man sieht, dasz er dem Satze des Widerspruchs, in demselben Augenblicke, als er durch ihn seinen Adelsbrief siegeln lässt, gerade widerspricht, und behauptet, es wäre nun erwiesen, dass er an sich selbst das sey, was er in sich selbst zwar nicht ist, sondern doch um erklärbar zu seyn, voraussetzen müsse. Um diesen Widerspruch zu verhehlen, ward, neben dem alten Selbst-Bewusstseyn ein neues erschaffen, das heisst erdichtet, der Mensch fand sich selbst wieder in einem Gesetze, dem er zu gehorchen zwar weder die Kraft noch die Lust hatte, aber doch, seiner gesetzgebenden Weisheit oder vielmehr Thorheit zur Ehre, gehorchen, und den Willen dazu in sich selbst erzwingen und erzeugen, das heisst ja offenbar: erdichten, erlügen sollte. Vom Gewissen sollte nun eigentlich gar nicht mehr die Rede seyn, denn mit und neben sich selbst sollte der Mensch nichts dulden, was nicht seine Selbst-That war, genug, dass er den leidigen Körper, die verwünschte Sinnlichkeit neben sich dulden mit sich herumtragen und mit ihnen sich balgen musste, und es war ganz folgerecht auch diesem Unwesen bald ein Ende zu machen was denn auch bald geschah, so wie es ohne alles zu verlieren, geschehen konnte, durch eine Erweiterung und Ausbildung des Widerspruchs, die das Ich als einen Gott beurkunden sollte, der, nun endlich in aller Wahrheit frey geworden alles was er nur wollte, auch sogleich thun könnte, ja nur das Wort gebrauchte um auszusprechen was, sobald es nur gedacht auch wircklich gemacht war, weil ja der Gedanke die wirckligste, die grösste, ja, wenn man genau spricht, die einzige That des freien, selbstbewussten Ichs unwidersprechlich ist. So lösete da das Ich den gordischen, so vielfach verschlungenen Knoten des Menschen-Daseins, dadurch dass es erstlich den Körper und die ganze Sinnlichkeit, als 
etwas neben sich Vorgefundenes, Fremdartiges in Gedanken rein von sich absonderte, vernichtete, das heisst verschlang und dann wieder aus sich selbst ganz wie es gewesen hervorbrachte. So war es dann entdeckt geworden und nachgewiesen, dasz der Mensch an und für sich selbst ein Gott wäre, der sich ein Gesetz gab, dem er widerstrebte und sich einen Körper schuf, der ihn beschränkte und ihm aneckelte, Alles freilich nur in Gedanken, um sich an sich selbst zu ergözen, und zu rächen, um sich auf einmal anbetungswürdig und verwerflich $\mathrm{zu}$ Allem und $\mathrm{zu}$ Nichts zu machen, sich auf einmal zu vergöttern und zu vernichten, zu bejahen und zu verneinen. Ja, rief Schelling aus, das ist eben das Göttliche, sich so über alle Gegen-Säze zu erheben, sich auf dem Indifferents-Punkte wo sie alle verschwinden, selbst zu setzen, und dann nur nicht wieder vergessen, dass sie verschwunden sind, und dass, wenn sie wieder erscheinen, sie uns nicht auf sondern unter dem Punkte erscheinen, wo sie lange genug ihr Wesen treiben mögen bis sie einander aufreiben, gegenseitig vernichten, indem unser Selbstbewusstseyn nicht absolut, sondern nur relativ in diesem Gegensatze als in der getrübten Erkenntniss besteht. Auf dem erhabenen Punkte wo wir uns setzen und lebendig anschauen, sind die Gegen-Sätze, als Wissen und Seyn in unserm Bewusst-Seyn Eins geworden so wie wir mit unsrem Bilde im Spiegel Eins sind, und diese göttliche Identität, ist sie einmal in unser Bewusstseyn eingetreten kann unmöglich wieder hinaustreten, so dass unsre Ewigkeit das Gewisseste von Allem, ja im Grunde das einzige Wissen ist.

Im Realen geht es freilich nicht an seine Ewigkeit zu behaupten, weil da, wo Alles nur im Werden ist von keinem absoluten Seyn die Rede seyn kann, im Idealen aber sind wir schon Alles was wir werden können, so dass die ewige Idee der Gottheit, die immer, um etwas zu erklären, vorausgesetzt werden muss, schon angefangen hat in uns sich zu realisieren, und, ein jedes Selbst als solches vernichtend, das Selbst-Bewusstseyn aller immer göttlicher darstellen wird. So kam es denn heraus, was hier unausfindbar in der tiefsten Finsterniss versteckt werden sollte, dass der Mensch an und für sich betrachtet, nur ein Körper ist, und nichts weiter, es kam hervor, weil es sich ergab, dass die Finsterniss, beym Lichte besehen, ein Nichts wird, das sich vor dem Lichte gar nicht zu behaupten, geschweige dann noch 
etwas zu verhehlen, vor dem Lichte zu verbergen fähig ist. Es ergab sich, dasz wircklich, wie Schelling sagte, das Licht aus der Finsterniss schien, aber freilich nicht, was er sich träumen liess, in der Finsterniss seine liebe Mutter erkannte, und sie als sein Schatten verehrte. Es erhellte, dass der Mensch in seiner Selbstheit befangen, im Grunde ein Nichts, ein zu vernichtendes ist, das mit dem Körper verschwindet, in sofern es nicht von der ewigen, göttlichen Idee in sich nicht als ein Selbst, sondern als eine Selbstverläugnung aufgenommen wird, und es war folglich nicht sich selbst, nicht sein Gegenbild [das] der Mensch in der göttlichen Idee, sondern es war ein Gegenbild der göttlichen Idee das er in sich erblickte, er sah, dasz er, den Körper hinweggedacht, in seiner Selbstheit nichts war, aber dasz er, den Körper mitgenommen, etwas Ewiges und Göttliches zu bedeuten, und im Geiste zu vertreten hätte. Nimmet man nun den Widerspruch hinweg, der sonnenklar aus dem Satze, dasz die göttliche Idee, Gottes Eben-Bild, ein Bild von dem sich selbst anchauenden Nichts sey, hervorleuchtet, räumen wir den Widerspruch hinweg, der weder zu verhehlen noch zu vergessen ist, weil die Wahrheit durchaus keine Gemeinschaft mit der Lüge haben mag, von keiner Indifferenz, und eben so wenig von einer Ausgleichung als von einer gegenseitigen Vernichtung, eben so wenig von einer Gleichgültigkeit gegen die Lüge, als von einer Identitæt mit ihr etwas wissen will, behalten wir nur von den Behauptungen was sich mit der Wahrheit möglicherweise vertragen kann, weil es ihr nicht widerspricht, dann haben wir die schlichte grosse Bibel-Wahrheit die sich nimmer ungerochen widersprechen lässt, die hohe Wahrheit: Gott sprach, lasset uns einen Menschen machen in unsrem Bilde und nach unsrer Gleichniss, und er machte den Menschen aus einem Erdenklosz und blies ihm ein den lebendigen Odem in seine Nase, und also ward der Mensch eine lebendige Seele. Darum müssen sie immer zu Schanden werden, die da sagen, der Mensch ist nur ein Körper, denn es gereicht ihnen unläugbar zur Schande, ihre göttliche Abkunft zu verneinen, obwohl es ihnen nicht möglich ist ohne sich selbst $\mathrm{zu}$ widersprechen, denn woher haben sie denn die Vorstellung von Etwas, das mehr und höher ist, als der Körper, wie kann der Mensch wenn er nicht das Bild eines göttlichen Menschen in sich trägt, in ein solches Bild sich verlieben, sich es 
in Gedanken aneignen, und als sein eignes Gegenbild in Worten ausdrücken, wie kann er sich einen almächtigen und alwissenden Gott denken, ohne es entweder selbst zu seyn, oder ein Bild davon in sich selbst erblickt zu haben?

Wenn wir nun aber, als Christen, die es glauben sowohl dasz der Mensch in Gottes Bild geschaffen ist, wie auch dasz er aus dem Bilde heraus durch die Sünde gefallen ist, wenn wir über die Grenzen des Menschen nachdenken, dann wundert es uns weder, dass einige das Bild verläugnen noch dass andere sich den zurückgebliebenen Schatten als ihr Eigenthum anmaassen, wir gedenken aber dankbar unsrer Aufrichtung in das Eben-Bild Gottes durch Jesum Christum, der das Eben-Bild des Vaters ist, in dem wir erschaffen sind, und können die Weisheit so wie die Liebe Gottes, nimmer genug bewundern. In dem eingebohrnen Sohne Gottes der in dem Vater ist, so wie der Vater in ihm, in $\mathrm{ihm}$ ist der Mensch erschaffen, er vereinigte den Menschen im Geiste mit sich, als seine menschliche Natur, und obschon der Mensch untreu ward, blieb er doch treu und machte in der Fülle der Zeiten die göttliche Natur menschlich, um die gefallene zur Erde gesunkene menschliche Natur wieder zu erheben, in sich aufzunehmen, so wie er sagt: die Stunde kommt und ist schon da, dass die Todten die Stimme des Sohnes Gottes hören werden, und die sie hören werden, die werden leben. Darum stehets geschrieben: er war in der Welt und die Welt ist durch ihn gemacht und die Welt kannte ihn nicht, er kam in sein Eigenthum, und die Seinigen nahmen ihn nicht auf; welche ihn aber ergriffen, denen gab er Macht Gottes Kinder zu werden; die an seinen Namen glauben.

Fragen wir nun, was Er, der Menschen Sohn an und für sich selbst war, so antwortet Johannes: das Wort im Anfange, das göttliche Wort, das Gott entsprach, denn Gott war das Wort, und in diesem Worte war das Leben, und das Leben war das Licht der Menschen. Dieses Wort ward Fleisch, war in sich selbst weit mehr, konnte sich selbst über dem Körper erblicken und sah dann sich in dem Vater und den Vater in sich, er sah in sich selbst körperlich des Menschen und geistig Gottes Sohn, seine Vernunft war sich der ewigen Idee, des göttlichen Eben-Bildes selbst bewusst, in einer wahren, lebendigen Anschauung seiner selbst, umschloss $\mathrm{Er}$ das ewige Leben ohne etwas auszu- 
schliessen was dazu gehörte, weil in ihm, der alles Seyn und Leben umfassenden Wahrheit, die Fülle der Gottheit nicht nur geistig sondern auch körperlich wohnte.

Hier sehen wir denn, sogleich was die Schellingsche Behauptung an sich Wahres hat, woraus sie entstanden und wie frevelhaft sie nicht nur mit Wörtern, sondern mit dem Worte spielt. Es ist nemlich wahr dasz der Mensch, als die lebendige Seele, wozu ihn der göttliche Hauch erhöhte, in der ewigen, göttlichen Idee, das heisst in dem lebendigen Worte, das der Sohn und die Wahrheit ist, ewig und göttlich war, und insofern ihn das Fleisch gewordene Wort wieder in sich aufgenommen hat, ewig und göttlich ist. Es ist aber ein lügenhaftes Märchen, dasz die göttliche Idee nicht das Ebenbild des göttlichen Seyns, sondern ein Vorbild dessen was nicht ist, also ein Bild der Leerheit seyn sollte, und eben so widersprechend ist es, $\mathrm{zu}$ behaupten, dasz die göttliche Idee auch nicht den Widerspruch, die Wahrheit nicht die Lüge ausschliessen sollte, weil man da behaupten müsste, dasz was man damit verneinte doch auch bejahet werden sollte, und dasz die ewige Idee, ohne seiner Selbst bewusst zu seyn sich selbst vernichtete und es auch nicht thäte.

Die Grund-Lüge der Natur-Philosophie ist demnach, dasz ein Nichts durch eigne Kraft, sich zu etwas erheben, dasz die Wahrheit aus der Lüge als seinem Elemente sich entwickeln könne; die Grund-Wahrheit aber die sie verkehrt und mit dessen Glanze sie die Augen verblendet, dürfen wir darüber nicht vergessen; denn es ist von grosser Wichtigkeit, dasz sie hervorgehoben und erkannt werde. Es ist das nothwendige Verhältniss des Zeitlichen zu dem Ewigen, das hier zuerst dem menschlichen Verstande kundgeworden, und in seiner Lebendigkeit ergriffen ist. Dieses wunderbare Verhältniss, das unläugbare Räthsel des MenschenLebens, das alle unsre Verhältnisse trägt und bedingt, war in der Ichheits-Lehre schon zum Grunde gelegt, aber sogleich wie zu Grunde gerichtet, denn die Idee des Alles erschaffenden Ichs war nur als ein todtgebornes Kind ans Licht gekommen, weil das nur reflectirende Ich den leeren Schatten seiner selbst zum Schöpfer machte, sein Schattenbild vergötterte, als wäre es möglich, bey Verneinung des göttlichen Lebens, noch göttliche Thaten zu verrichten. Die Idee des alles Geistige umfassenden, alles Körperliche erschaffenden Ichs ist freilich das almächtige, göttliche Wort, 
aber von allem göttlichen Leben entäussert, in die irdische Individualität hineingebannt, als wenn man in den prophetischen Reden das göttliche Ich für eine blosse Rede-Figur erklären und ihm gleichwohl Alles, was es von sich aussagt, zuschreiben wollte. Das entdeckte Schelling war all $\mathrm{zu}$ arg, indem es das Nichts, in seiner Nichtigkeit aufgefasst, indem es die Unmöglichkeit vergötterte, und damit der alle Thaten bedingenden, alles Leben erzeugenden Kraft-Idee, also auch dem Grundgesetze des hinreichenden Grundes Hohn sprach, Alles der tollsten Willkürlichkeit des Denkens Preis gab. Alles was nur bedingterweise da ist, so dachte er, setzt nothwendig das Unbedingte, das Relative das Absolute voraus, man kann sich die Veränderung nicht denken, ohne Etwas zu denken das verändert wird, und das Veränderliche muss dann entweder durch eine unveränderliche Kraft oder durch ein Treiben seiner Selbst verändert werden, das Zeitliche muss entweder die Schöpfung oder die Selbst-Offenbarung, die Selbst-Entwickelung eines Ewigen seyn. Hier stand er auf dem grossen Kreuzwege des Denkens, wo der Gedanke des Ewigen, Alles Bedingenden Unbedingten, als das erste unentbehrliche Glied der Ideen-Kette sich der Vernunft aufdringt, und nur zwei Wege stehen hier dem Denker offen: er muss sich selbst entweder verläugnen oder vergöttern, in der ewigen Idee entweder Gott oder sich selbst setzen. Das Letztere nun erwählte Schelling er setzte sich anstatt Gottes, an Gottes Stätte, und man sieht ja leicht, dasz er es that, weil es weit bequemer, erhabener, und zugleich erfreulicher ist, auf dem Throne des Ewigen zu sitzen als im Staube danieder zu liegen ja, wenn man die Lage des Menschen erwägt, springt es sogleich in die Augen, dasz ihn, wenn er das Göttliche nicht abläugnen darf, eine beinahe unwiderstehliche Lust, selbst ein Gott zu werden, anwandeln muss; denn, so ein lebendiger Gott über uns waltet, sind wir nothwendig alle, die wir nach Unabhängigkeit strebten, insgesammt tollkühne Frevler, die, wenn anders, nur durch die peinlichste Reue und die tiefste Demuth, dem vernichtenden Blitze entgehen können, und wer mag, nicht nur einzelne Thaten, sondern sein ganzes Thun und Treiben verdammen und bereuen, wer mag sich demüthigen, ja, gleichsam vernichten, wenn noch Hoffnung da ist sein Vergehen zu beschönigen, und seine Ehre zu retten. Mit Recht nennt man denn auch aus diesem Gesichts- 
Punkte die Schellingsche Weisheit Natur-Philosophie, denn sie ist für den Sünder, der von dem Geistigen ergriffen wird, die einzig natürliche Anschauung des sich selbst widersprechenden Menschen-Lebens, eine Vergötterung des Widerspruchs, der nicht zu heben noch zu lösen ist, eine Fetish-Anbetung des grossen gordischen Knotens, der nur durch das Schwerdt, das scheidet Seel und Geist, auch Mark und Bein, zu zerschneiden ist. Es ist ja auch unläugbar ein erhabener und zugleich erhebender Gedanke, dasz die ewige Idee der Gottheit um realisirt zu werden, sich der Zeitlichkeit und Eitelkeit hingab, es sich gefallen liess in die Endlichkeit herab zu versinken, in den Staub sich zu verhüllen und ein zu kerkern, um durch den Kampf mit Hüllen und mit Fesseln sich seiner Kraft und seiner Selbst bewusst, göttlich bewusst zu werden, so dasz der Mensch, wenn er das Götliche gewahr wird, nichts zu fürchten, nichts zu bereuen, nichts sich $\mathrm{zu}$ versagen, sondern alles $\mathrm{zu}$ hoffen, $\mathrm{zu}$ erstreben und zu erleben hat. Er muss freilich bedauren, dasz er so lange nur ein Thier gewesen, und ein solches Vergessen seiner göttlichen Abkunft setzt ja wohl auch eine dunkle Schuld voraus, ein thörichtes Streben in sich selbst abgeschlossen zu bestehen, wodurch der Geist sich selbst von der göttlichen Idee der gesammten Natur ausschliessend sich geistig vernichtete, aber es muss ja hier eine herbe Nothwendigkeit, ein finstres, unerbittliches Schicksal obgewaltet haben, denn freiwillig, mit offnen Augen, thut ja doch wohl kein Geist Verzicht auf ein ewiges, göttliches Leben, und wenn der Irrthum entdeckt wird, ist er sogleich vergeben, denn er ist durch die Anschauung des Wahren ausgelöscht.

Es hällt nicht schwer eine solche Luftblase zu zerstören, aber wohl ihre Liebhaber davon zu überzeugen, dasz sie wircklich vernichtet sey, denn wer sich den Widerspruch so zu eigen gemacht hat, dasz er die tiefste Weisheit darin findet sich selbst gradezu zu widersprechen, verfährt ganz folgerecht indem er die vor seinen Augen vernichtete Blase, sogleich wiederherstellt, und damit die Göttlichkeit des Ungrundes, aus dem Alles werden kann, ubesiegbar erwiesen zu haben glaubt. Vielleicht möchte es bei einigen die grösste Wirckung thun, wenn man den Streit ganz ins Practische hinüber spielte, und sich nur darauf beschränckte, zu entwickeln was nothwendig erfolgen müsste, wenn der Mensch durch die intellectuelle Anschauung seiner 
selbst in der ewigen Idee, dem Geiste nach, wircklich vergöttert, oder, um genauer zu reden, seine Mensch-Werdung begreifend, seiner Gott-Werdung gewiss würde. Gesetzt also, nicht eingestanden, gesetzt, wie die Natur-Philosophen Alles nur setzen, es wäre möglich, dasz der Mensch aus göttlichem Saamen entsprossen, sich in die Zeitlichkeit herabgesenkt, in den zerbrechlichen Körper hineingebannt, als den werdenden Gott, entdecken könnte, und dasz die ewige göttliche Idee, zwar unbewusst aber doch nur durch eine ihr innwohnende freie Nothwendigkeit gezwungen, sich diesen Schicksal unterzogen hätte, so müsste sich doch nothwendig, mit dem göttlichen Bewusstseyn die göttliche Kraft zugleich entwickeln, und der Mensch vom Geiste Gottes erfüllt, der Gott im Geiste müsste nothwendig, um sich als die wahre Kraft-Idee zu beurkunden, die Thaten der unbewussten Ur-Kraft mit ähnlichen aufwiegen; denn wer sich göttlich nennt muss auch göttlich seyn, oder lächerlich werden.

Um diess im hellsten Lichte zu sehen dürfen wir nur ihn betrachten, bey dessen göttlichem Leben als Vorbilde die NaturPhilosophie selbst gefällig $\mathrm{zu}$ verweilen pflegt; denn ist das Evangelium nur eine Weissagung von ihr, muss ja die Weissagung durch sie in Erfüllung gehen, und das Evangelium somit eine vorläufige Lebens-Geschichte des sich in seiner Göttlichkeit auffassenden Menschen seyn, der es ihm obliegt in allen Stücken $\mathrm{zu}$ entsprechen. Es hilft gar nicht, wenn man sagen wollte, der Göttliche hat noch nicht das Ziel erreicht noch nicht die FeuerTaufe empfangen, denn warum hat er denn sein Lehr-Amt schon angetreten, warum bleibt er denn nicht, wie sichs gebührt seinen Eltern: dem Glauben und der Liebe unterthan, wie wagt er es, ohne die heilige Weihe, durch die grosse Gewissens-Taufe, und damit die Heiligsprechung empfangen zu haben, Sünden zu vergeben und seinen Jüngern den Geist, der ihn selbst noch nicht erfüllt, zu verheissen? Sollen vielleicht, wie einige geflüstert haben, die Erscheinungen des thierischen Magnetismus die Grossthaten seyn, wodurch sich der Alles erschaffende Alles vermögende göttliche Geist beurkundet? Nun, das würde freilich eine Auflösung des Knotens seyn, die unwidersprechlich zeigte, dasz das Welt-Drama, im Kopfe der Natur-Philosophen gespielt, wie sie selbst sagen, ein tragicomisches genannt werden müsse, aber wer nicht auf Lachen erpicht, sondern nach Wahrheit begierig 
ist, sieht doch sogleich ein, dasz ein so armseliger Geist, der nur mit genauer Noth solche Schlösser in die Luft bauet, nicht Derselbe ist, der im Anfange sprach und es geschah, nicht der WeltSchöpfer ist. Bedürfte es noch eines Erweises, wie lächerlich es ist, sich auf die Erscheinungen des Magnetismus, wären sie auch weit grösser und bewährter, als es noch der Fall ist, als auf Grossthaten des Geistes zu berufen, dann brauchte man nur zu bemerken, dasz sie ganz unabhängig von den Anschauungen des Thäters stattfmden, so dasz der gröbste Materialist, wenn er nur will, eben so gut als der feinste Idealist magnetisiren kann, so dasz der Natur-Philosoph, wenn er sich als den göttlichen Menschen-Sohn behaupten will, durchaus andere Gross-Thaten, kraft seiner Anschauung, verrichten muss, und solche Grossthaten, die unwidersprechlich zeigen, dasz die Natur-Gesetze ihn gar nicht fesseln, sondern, nur im Algemeinen gelten, weil er es in seiner Weisheit ersprieslich findet. Dieses aber wird nur bestätiget, wenn er die Gesetze in gewissen Verhältnissen augenblicklich suspendirt, wie es der Fall war, wenn Jesus Wasser in Wein verwandelte wenn er fünftausend Männer mit fünf Brodten so speisete, dasz die Überbleibsel mehr war als der ganze Vorrath, oder wenn er den schon verfäulenden Lazarus ins Leben zurückrief; denn nur solche Thaten zeugen von einer göttlichen Almacht, die, wenn es ihr beliebt, die ganze Welt umschaffen kann, sie also auch im Anfange hervorrufen könnte. Es bleibt dann den Natur-Philosophen Nicht übrig, ausser die Schmähungen des groben fleischlichen Sinnes, des jüdischen Heisshungers nach handgreiflichen Wundern zu wiederholen und zu erhärten, aber sie stehen des ungeachtet, wie die Ochsen am Berge und können es nicht läugnen, dasz wer das Grösste vermag, auch das Geringste thun können müsse, und sie mögen auch die göttliche That der Welt-Schöpfung so tief herabsetzen, wie es ihnen beliebt, es gereicht ihnen um soviel mehr zur Schande, dasz sie auch nicht im Geringsten ihren angemaassten Titel entsprechen können, denn wer nicht einmal Wasser in Wein verwandeln kann, wie sollte ers vermögen wie es dem Welt-Heilande geziemt, die Sünde zu vertilgen und den Tod zu besiegen?

Doch, wenn man auch zugeben wollte, dasz alle die WunderThaten, die der Heiland verrichtete, nur durch eine geistige Deutung im Geist und in der Wahrheit aufgefasset, wahrhaft göttlich 
würden, und dasz somit die Natur-Philosophie durch rein geistige Thaten ihre Göttlichkeit bewähren könnte, es bliebe doch immer gewiss, dasz es unläugbar göttliche Thaten seyn müssten, aus welchen es erhellte, dasz der Thäter, wenn er sich so tief herablassen wollte, auch die Körper-Welt auf das wunderbarste $\mathrm{zu}$ beherrschen und zu gestalten vermöchte; denn der Geist der sich den Alles erzeugenden nennt, kann die Körper-Welt durchaus nicht für ein ihm unzugängliches Todten-Reich, wo fremde Mächte walten erklären ohne sich damit als den Lügen-Geist selbst zu bezeichnen. Freilich haben es die Lügen-Geister dennoch von Alters her kühn gewagt, alle Ansinnungen ihre Göttlichkeit durch augenscheinlich göttliche Thaten zu erweisen, auf dieser albernen Weise abzuweisen und die alten Gnostiker thaten es so vollständig und folgerecht, dasz sie den Welt-Schöpfer rein von ihrem höchsten Gott absonderten und seine Uebermacht nicht nur im Körperlichen, sondern auch im Physischen anerkannten, wer sieht aber nicht, dasz es eine Tollkühnheit ist, die ins Tollhaus gehört, und doch müsste die Natur-Philosophie, um folgerecht zu werden den Unsinn eben so weit treiben, denn wenn ein Geist aus dem Munde eines Menschen spricht, kann er doch unmöglich, ohne sich in einem Athemzuge selbst zu widersprechen, behaupten dasz er sich zu der Körper-Welt nicht herablassen kann oder will, und muss dann entweder seine Uebermacht bewähren oder die eines andern anerkennen. Schon die Gnostiker, deren Irrthum bei weitem nicht so ungereimt als lügenhaft ist, fühlten es indessen, dasz der Geist, der sich den Geist des Höchsten nannte, ob er auch, durch ein unaussprechliches Geheimnis der Liebe, sich gedrungen fühlte, den Demiurgos mit blinder Willkühr in der, geistig genommen nichtigen Körperund Seelen-Welt walten zu lassen, doch, um diesem unseligen Walten einen Sinn zu geben, und Maass und Ziel zu setzen, insgeheim Alles lenken, und seine Göttlichkeit auch in der Körper-Welt, da wo sie durch die Seele mit dem Geiste verbunden erscheint, in dem Menschen bewähren müsste. Daher zerbrachen sich die Gnostiker den Kopf um zu zeigen, wie die Geschichte des alten Testaments, der prophetischen Zeit, wider den Willen des Demiurgos und der von ihm begeisterten Propheten selbst, ihre Anschauungen bestätigte, und ihre Erscheinung, als die Fülle der Zeiten bezweckte, wie auch die Natur-Philosophie 
versucht hat und, der grossen Schwierigkeiten ungeachtet, die sich heutzutage entgegenstellen, noch ferner versuchen muss, wenn sie ihr lügenhaftes Mährchen unter dem Schleier der Wahrscheinlichkeit zu verbergen noch ferner gedenket.

Fra Grundtvig-arkivet (fasc. 168.3, 22 blade) 